\title{
TO STUDY THE ASSOCIATION OF SOCIODEMOGRAPHY AS A RISK FACTOR FOR ECLAMPSIA
}

\author{
Namrata Verma ${ }^{1}$, Renu Mohan², Harish Chandra Tiwari' ${ }^{3}$,Babita Kapoor 4
}

${ }_{13}^{\text {rd }}$ Year Junior Resident, Department of Obstetrics and Gynaecology, Baba Raghav Das Medical College, Gorakhpur, Uttar Pradesh. ${ }_{2}^{2}$ Associate Professor, Department of Obstetrics and Gynaecology, Baba Raghav Das Medical College, Gorakhpur, Uttar Pradesh. ${ }^{3}$ Lecturer Health Education, Department of Obstetrics and Gynaecology, Baba Raghav Das Medical College, Gorakhpur, Uttar Pradesh. ${ }^{4}$ Assistant Professor, Department of Obstetrics and Gynaecology, Baba Raghav Das Medical College, Gorakhpur, Uttar Pradesh.

\section{ABSTRACT}

\section{BACKGROUND}

Eclampsia is a preventable disease be prevented by making women aware of the avoidable risk factors during their antenatal visits and thereby decreasing the incidence of eclampsia and associated morbidity, mortality and perinatal outcome.

Aim- To study the association of sociodemography as a risk factor for eclampsia.

Objective- To compare the various parameters of sociodemographic risk factors (namely age, residence, education and socioeconomic status) between the eclamptic and the patients admitted for delivery with no complications.

\section{MATERIALS AND METHODS}

This was a case-control study done in the labour room of Nehru Chikitsalaya, BRD Medical College, Gorakhpur over a period of 1 year from July 2015 to June 2016 on 282 admitted women. This is a tertiary care hospital and its maternity service is a referral in the care of high risk pregnant women throughout the district. All women selected for the study were divided into two groups, cases and controls. Cases were the patients admitted to labour room with BP $>140 / 90 \mathrm{mmHg}$, Urine Protein $>+1$, with convulsions. Controls were the patients admitted to labour room with $\mathrm{BP}<140 / 90 \mathrm{mmHg}$, Urine Protein negative, without convulsions. Their age, education, residence and socioeconomic status were compared and analysed. The $\mathrm{X}^{2}$ test was used to determine levels of statistical significance wherever appropriate.

\section{RESULTS}

Majority of the cases taken into the study were from less than 20 years of age group and 21-30 years of age i.e., $44.68 \%$ and $51.77 \%$ respectively. High proportion of eclampsias $68.08 \%$ belong to rural area, only $31.92 \%$ belong to urban area. Majority of eclampsia (89.36\%) cases were associated with high rate of illiteracy (89.36\%) as compared to controls (47.51\%), belonging to rural area (68.08\%) and low socioeconomic conditions. Maximum no. of eclamptic women were from low socioeconomic class i.e., $70.92 \%$ from class V, 26.24\% from class IV, 1.41\% from class III and II each and no women from class I according to Modified B G Prasad Socioeconomic Classification. In our study statistically significant association was observed between eclampsia and risk factors.

\section{CONCLUSION}

Eclampsia is a preventable disease by making the patient aware of the risk factors which can be avoided and thereby decreasing the incidence of eclampsia and associated morbidity and mortality.

\section{KEYWORDS}

Eclampsia, Sociodemography.

HOW TO CITE THIS ARTICLE: Verma N, Mohan R, Tiwari HC, et al. To study the association of sociodemography as a risk factor for eclampsia. J. Evolution Med. Dent. Sci. 2017;6(59):4375-4378, DOI: 10.14260/Jemds/2017/946

\section{BACKGROUND}

Eclampsia is characterised by sudden onset of generalised tonic-clonic convulsions, coma in pregnancy or postpartum period unrelated to other cerebral conditions in patients with symptoms of pre-eclampsia. ${ }^{1}$ Depending on time of occurrence of convulsions before, during and after labour eclampsia is designated as antepartum, intrapartum and postpartum. The frequency of timing of eclampsia reported in literature ranges from 38-53\% antepartum, 15-20\%

Financial or Other, Competing Interest: None.

Submission 19-06-2017, Peer Review 12-07-2017,

Acceptance 19-07-2017, Published 24-07-2017.

Corresponding Author:

Dr. Namrata Verma,

Room No. 19, Indira Girls Hostel,

Baba Raghav Das Medical College,

Gorakhpur, Uttar Pradesh.

E-mail: drsudhanshu777@gmail.com

DOI: $10.14260 /$ jemds $/ 2017 / 946$ intrapartum, $11-44 \%$ postpartum. Most antepartum eclampsia occurs in III trimester (90\%). Eclampsia occurring before 20 weeks is usually associated with molar pregnancy. Most post-partum eclampsia occurs within 48 hours. ${ }^{1}$ Preeclampsia or eclampsia accounts for $25 \%$ of cases of maternal mortality worldwide (Agrawal S, Fledderjohann J). ${ }^{2}$

Incidence of eclampsia is 1 in 2000 pregnancies in developed countries, $1 / 100$ to $1 / 1700$ in developing countries (Duckitt K, Harrington D. BMJ 2005 March 12). ${ }^{3}$ Pre-eclampsia affects about $5 \%$ of pregnancies while eclampsia affects $1.4 \%$ pregnancies. Maternal mortality rate of eclampsia was found to be $16 \%$ in U.S. in a study from 2000 to $2006,18 \%$ in U.K. from 2003 to 2005 and $8 \%$ to $14 \%$ in developing countries. ${ }^{4}$

Eclampsia contributes to $9 \%$ of all maternal deaths in Nepal (our neighbouring country situated $90 \mathrm{~km}$ away from Gorakhpur). ${ }^{5}$

In India, incidence of eclampsia is $1.5 \%$ of pregnancies. ${ }^{5}$ In Gorakhpur, the prevalence is $5.28 \%$ according to the 
indoor admission register of Obstetrics \& Gynaecology Department of BRDMC. Gorakhpur.

Aetiology of eclampsia is characterised by suboptimal uteroplacental perfusion associated with a maternal inflammatory response, maternal and vascular endothelial dysfunction. Placenta has a pivotal role in the pathogenesis. ${ }^{1}$

Finding noted on MRI is subcortical white matter oedema involving the posterior portions of the cerebral hemispheres bilaterally with areas of petechial haemorrhages, ischaemia particularly in occipital with parietal occipital regions. ${ }^{1}$

\section{Risk Factors}

1. First pregnancy.

2. First pregnancy with a new partner.

3. Preeclampsia or eclampsia in previous pregnancy.

4. 10 years or more since last pregnancy.

5. Age $>40$ years.

6. BMI of 35 or more at presentation.

7. Family history of preeclampsia or eclampsia.

8. Certain underlying medical conditions:

- Pre-exiting HTN.

- Pre-existing renal disease.

- Pre exiting diabetes.

- Anti-phospholipid antibody presence.

9. Poor outcome of previous pregnancy including IUGR abruption placenta.

10. Multifoetal gestation, hydatid mole, foetal hydrops and primigravidae.

11. Lower socioeconomic status.

12. Protein $\mathrm{C}$ with protein $\mathrm{S}$ deficiency.

13. Antithrombin deficiency.

14. Vascular and connective tissue disorders.

Eclampsia is associated with elevated maternal with foetal morbidity with mortality. Major maternal complications include placental abruption (7-10\%), acute renal failure $(5-10 \%)$, HELLP syndromes $(2 / 5 \%)$. The most common causes of maternal death are intracranial bleeding and acute renal failure secondary to abruptio placenta. The most common cause of perinatal death are prematurity and foetal asphyxia. ${ }^{1}$

The diagnosis of eclampsia is usually clear when women present with seizures, hypertension and proteinuria. Hypertension is the hallmark for the diagnosis of eclampsia. Hypertension may be severe (20-54\% of cases) or mild (30$60 \%$ of cases). Unfortunately, in approximately $15 \%$ of the cases, hypertension and proteinuria may not be present. However, when seizures develop in a pregnant woman without a history of seizure disorders, eclampsia should be the diagnosis unless proven otherwise. The presence of haemoconcentration, elevated liver enzymes, elevated LDH, and thrombocytopenia also help in correct diagnosis when high blood pressure and proteinuria are not present. ${ }^{1}$

Management of eclampsia includes control of convulsions, control of hypertension, delivery of the foetus. ABC of resuscitation (airway, breathing and circulation), the initial step is to prevent maternal injury and maintain cardiorespiratory function. Magnesium sulfate is the drug of choice in treatment of eclampsia given according to the Pritchard's Regime. The first line antihypertensive drug is labetalol followed by nifedipine. The goal should be to maintain systolic blood pressure between 140 and 160 $\mathrm{mmHg}$ and diastolic blood pressure between 90 and 105 $\mathrm{mmHg}$. Delivery is the only definitive treatment for eclampsia. However, every attempt should be made to stabilise the mother before attempting delivery. ${ }^{1}$

\section{MATERIALS AND METHODS}

This was an observational case-control study done in the labour room of Nehru Chikitsalaya, BRD Medical College Gorakhpur over a period of 1 year from July 2015 to June 2016 on 282 women. Our hospital is a tertiary care centre and its maternity services serve as a referral in the care of high risk pregnant women throughout the district. Women were divided into two groups, cases and controls. Cases were the women with gestational age more than 20 weeks, blood pressure more or equal to $140 / 90 \mathrm{mmHg}$ and urine proteinuria greater than or equal to $300 \mathrm{mg}$ per 24-hour urine collection or protein/creatinine ratio more than or equal to 0.3 or dipstick reading of $1+$. And in the absence of proteinuria, cases were selected as new-onset hypertension with the new onset of any of the following:

- Thrombocytopenia (platelet count less than $100000 /$ microlitre), Impaired liver function (liver enzymes raised to twice the normal concentration).

- Progressive renal insufficiency (S. Creatinine more than $1.1 \mathrm{mg} / \mathrm{dL}$ ), pulmonary oedema.

- New-onset cerebral or visual disturbances and with convulsions.

Controls were the women with BP less than 140/90 $\mathrm{mmHg}$, negative urine protein, with no signs and symptoms of eclampsia and having no other associated complications. Informed consent from the eligible candidates was taken and in case of unconscious eclamptic women consent was taken from her attendants. The two groups were compared for the age, education, residence and socioeconomic status. Data collected and analysed. The $\mathrm{X}^{2}$ test was used to determine levels of statistical significance where appropriate.

\section{Sample Size}

- $\quad$ Sample size was calculated on assuming odd's ratio -2 .

- Proportion of controls exposed for risk factor $=30 \%$.

- Power of study $80 \%$.

- At $95 \%$ of confidence interval.

- $\quad$ Estimated sample size 141 per group.

- $\quad$ Total sample size $=282$.

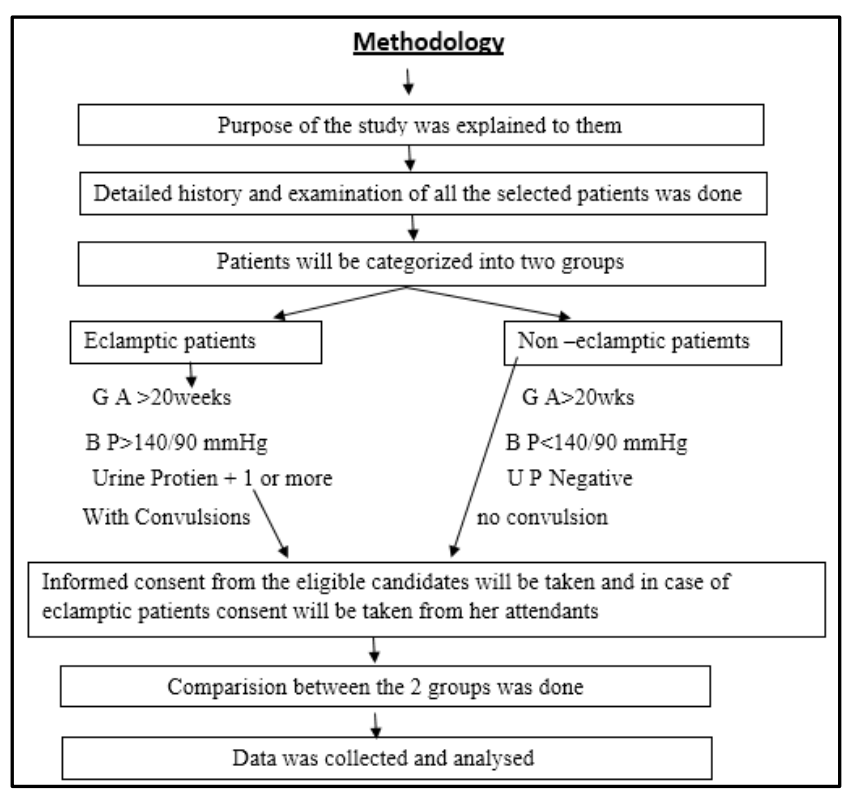




\section{RESULTS}

Present study shows that the majority of the cases taken into the study were from early age group, illiterates, belonging to rural area and low socioeconomic status. Majority of eclamptic women belong to less than 20 years of age group and $21-30$ years of age i.e. $44.68 \%$ and $51.77 \%$ respectively $\left[\mathrm{X}^{2}=27.1 ; \mathrm{df}=3 ; \mathrm{P}=<0.05(\mathrm{~s})\right] .68 .08 \%$ of eclampsias belong to rural area, only $31.92 \%$ belong to urban area $\left[\mathrm{X}^{2}=25.1 ; \mathrm{df}\right.$ $=1 ; \mathrm{P}=<0.05(\mathrm{~s})]$. Majority of eclampsia (89.36\%) cases were associated with high rate of illiteracy as compared to controls $\left[\mathrm{X}^{2}=57.1 ; \mathrm{df}=1 ; \mathrm{P}=<0.05(\mathrm{~s})\right]$. Maximum no. of eclamptic women were from low socioeconomic class i.e., $70.92 \%$ from class V, $26.24 \%$ from lass IV, 1.41\% from class III and II each and no women from class I according to modified BG Prasad socioeconomic classification.

\begin{tabular}{|c|c|c|c|c|}
\hline \multirow{2}{*}{ Characteristics } & \multicolumn{2}{|c|}{ Cases } & \multicolumn{2}{c|}{ Controls } \\
\cline { 2 - 5 } & $\begin{array}{c}\text { No. of } \\
\text { Cases }\end{array}$ & $\mathbf{\%}$ & $\begin{array}{c}\text { No. of } \\
\text { Controls }\end{array}$ & $\%$ \\
\hline $\begin{array}{c}\text { Age group }<20 \\
\text { years }\end{array}$ & 63 & $44.68 \%$ & 30 & $21.27 \%$ \\
\hline 21-30 years & 73 & $51.77 \%$ & 85 & $60.28 \%$ \\
\hline 31-40 years & 5 & $3.54 \%$ & 24 & $17.02 \%$ \\
\hline$>40$ years & 0 & $0 \%$ & 2 & $1.41 \%$ \\
\hline Residence Rural & 96 & $68.08 \%$ & 54 & $38.2 \%$ \\
\hline Urban & 45 & $31.92 \%$ & 87 & $61.8 \%$ \\
\hline Education literate & 15 & $10.63 \%$ & 74 & $52.48 \%$ \\
\hline Illiterate & 126 & $89.36 \%$ & 67 & $47.51 \%$ \\
\hline $\begin{array}{c}\text { Socioeconomic } \\
\text { Status I }\end{array}$ & 0 & $0 \%$ & 0 & $0 \%$ \\
\hline II & 2 & $1.41 \%$ & 28 & $19.85 \%$ \\
\hline III & 2 & $1.41 \%$ & 38 & $26.95 \%$ \\
\hline IV & 37 & $26.245 \%$ & 15 & $10.63 \%$ \\
\hline V & 100 & $70.92 \%$ & 60 & $42.555 \%$ \\
\hline Total & $\mathbf{1 4 1}$ & $\mathbf{1 0 0 \%}$ & $\mathbf{1 4 1}$ & $\mathbf{1 0 0 \%}$ \\
\hline \multicolumn{2}{|c|}{ Table 1 } \\
\hline
\end{tabular}

\section{DISCUSSION}

The present observational case-control study was conducted in the Department of Obstetrics and Gynaecology, BRD Medical College, Gorakhpur. A total of 282 women were included in the study. Women were divided into two groups, cases and controls including 141 patients in each group according to the criteria mentioned previously. The two groups were compared for the age, residential locality, education and socioeconomic status and statistically significant association was observed between these various factors and eclampsia as maximum women taken into the study were from early age group, illiterate, belonging to rural area and low socioeconomic status.

In the study, it was found that majority of eclampsia cases belonged to early age group i.e. $44.68 \%$ eclampsia cases from less than 20 years of age group, 51.77\% from 21-30 years of age group, followed by only $3.54 \%$ from $31-40$ years of age group and no women of more than 40 years of age as compared to non-eclamptic women i.e., only $21.27 \%$ from less than 20 years of age, $60.28 \%$ from $21-30$ years of age, $17.02 \%$ from $31-40$ years of age and $1.41 \%$ of more than 40 years of age and respectively. The association of eclampsia with age was found to be statistically significant, $X^{2}=27.1$; df $=3 ; \mathrm{P}=<0.05(\mathrm{~s})$. Same results were shown in the study conducted by Ramesh $\mathrm{K}^{7}$ et al on 'Sociodemographic and Other Risk Factors of Preeclampsia' at a Tertiary Care Hospital, Karnataka. In their study, the mean age of cases (21.16 years) was less than the controls (23.56 years). Pregnant women of age less than 20 years were 3.87 times at risk of developing preeclampsia compared to age of more than 20 years (OR 3.87, 95 \% CI: 2.32-6.44). A Pal et al also conducted a study on eclampsia- scenario in a hospital, which reveals that the incidence of eclampsia $<20$ years was $6.97 \%$. Present study depicted that $68.08 \%$ of eclampsia belong to rural area, only $31.92 \%$ belong to urban area where as in non eclamptic women $61.8 \%$ were from urban area and only $38.2 \%$ belong to rural area. The association of eclampsia with residential locality was statistically significant $X^{2}=25.1 ; \mathrm{df}=$ 1; $\mathrm{P}=<0.05$ (s). Other study by $\mathrm{A} \mathrm{Pal}^{8}$ et al on eclampsiascenario in a hospital also have shown the same result that the majority $(83.39 \%)$ of cases were from rural areas.

Present study observed that majority of eclampsia (89.36 $\%$ ) cases were associated with high rate of illiteracy as compared to controls (47.51\%). The association of eclampsia with education was found to be statistically significant, $\mathrm{X}^{2}=$ 57.1; $\mathrm{df}=1 ; \mathrm{P}=<0.05$. A study by Ramesh $\mathrm{K}^{7}$ at el has shown similar results that preeclampsia showed significant association between maternal education, income and preeclampsia, Silva $^{8}$ et al also found in their study that Women with low educational level were more likely to develop preeclampsia (Odd's ratio 5.12; 95\% confidence interval: 2.20, 11.93 ) than women with high educational level.

\section{CONCLUSION}

Eclampsia continues to be a major cause of maternal and perinatal morbidity and mortality in developing countries. There is a need for continued in-depth studies on its characteristics and pattern in order to prevent the disease and improve the clinical outcome. The present study helped to determine the sociodemographic patterns among eclamptic women admitted to our hospital Nehru Chikitsalaya, Baba Raghav Das Medical College, Gorakhpur, Uttar Pradesh and compared them with non eclamptic women. Through our study we concluded that all the pregnant women should be screened along with a given questionnaire during their first scheduled ante natal visit at grass root level i.e. at any level of medical care centre. Awareness should be created among the women who are illiterate, belonging to rural area and low socioeconomic status so that the risk factors of eclampsia can be identified in early pregnancy and preventing the patients to land up in eclampsia. This will help in decreasing the incidence of eclampsia and associated mortality and morbidity.

\section{REFERENCES}

[1] Arias' practical guide to high risk pregnancy \& delivery. A South Asian perspective. $4^{\text {th }}$ edn. 2015.

[2] Agrawal S, Fledderjohann J, Vellakkal S, et al. Studied on association of adequately diversified dietary intake and iron and folic acid supplementation during pregnancy is associated with a reduced occurrence of symptoms suggestive of pre-eclampsia or eclampsia in Indian women. PLoS One 2015;10(3):e0119120. 


\section{Jemds.com}

[3] Duckitt K, Harringt D. Risk factors for pre-eclampsia at antenatal booking: systematic review of controlled studies. BMJ 2005;330(7491):565.

[4] James D. High risk pregnancy. $4^{\text {th }}$ edn. Emeritus professor of fetomaternal medicine, Foundation Director of Medical Education, Queen's Medical Centre, Nottingham, UK: 2012.

[5] Duley L. Maternal mortality associated with hypertensive disorders of pregnancy in Africa, Asia, Latin America and the Caribbean. Br J Obstet Gynecol 1992;99(7):547-53.

[6] Nobis PN, Hajong A. Eclampsia in India through the decades. J Obstet Gynaecol India 2016;66(Suppl 1):172-6.

\section{Original Research Article}

[7] Ramesh K, Sibai B, Dekker G, et al. Geographic variation in the incidence of hypertension in pregnancy. World Health Organisation International Collaborative Study of hypertension disorders of pregnancy. Am J Obstet Gynaecol 1988;158(1):80-3.

[8] Silva LM, Coolman M, Steegers EA, et al. Low socioeconomic status is a risk factor for preeclampsia: the Generation $\mathrm{R}$ Study. Journal of Hypertension 2008;26(6):1200-8.

[9] Pal A, Bhattacharya R, Adhikari S, et al. Eclampsiascenario in a hospital - a ten years study. Bangladesh Medical Research Council Bulletin 2011;37(2):66-70. 